procurement"). Indeed, by a logical twist of which Cardinal Morton would have been proud, it suggests that a low output per man (one third of the American figure) actually offers the British industry a "most powerful advantage" in a "skill-intensive" industry. Without going into any detail, it reports the results of a study which suggests that British costs are very much lower than American ones; on a run of fifty aeroplanes, the advantage is 40 per cent. An aircraft which in Britain would break even on a production run of 130 would need a run of 410 in the United States. "With anything like a comparable run, the British cost advantage is very great", it declares.

It continues in the same vein, showing that Government money invested in the aircraft industry is well spent. The ratio between net aid and sales for the VC 10, the Trident and the BAC $1-11$ series is 1 to 14.5. This would have been even better if the VC 10 and Trident had not been tailored so closely to British airline requirements - or even worse if the Concorde had been included. But it was omitted because, says the pamphlet, "it was realized from the outset that although it would achieve very large export sales, it was not a commercial venture in the normal sense". It is a pity that the $\mathrm{SBAC}$ did not share this realization with the public a little sooner.

This knockabout stuff sets the scene for the second half of the pamphlet, which tells the Government where it should spend its money next. 'The answer, unfortunately, is not very helpful, for the SBAC is in favour of supporting almost every kind of aircraft it is possible to think of. In the civil field, for example, it favours supersonic transports, short/medium range subsonic transports, V/STOL inter-city transports, medium size short take-off transports, turbine powered executive aircraft, and light transports for short-range freight and passenger operation. The military list is almost as comprehensive; about the only thing the SBAC fails to mention is the dirigible. In space, oddly enough, its heart and that of $\mathrm{Mr}$ Wedgwood Benn seem to beat as one; it favours fewer international obligations, more emphasis on applications satellites, and the development of a Europcan launcher only as a long term project. As a declaration of self-confidence and enthusiasm the pamphlet is a complete success; but it leaves the Government to make the difficult decisions.

\section{UNIVERSITIES AND GOVERNMENT Hand in Glove}

'lHe University of Surrey and the Ministry of Technology's Royal Aircraft Establishment (RAE) have formally joined forces in research and teaching in a number of departments of both organizations. This is the fifth of a series of links formed between British universitics and Government research establishments and is possibly the most far reaching in its arrangements for collaborative higher degree work.

During the five years for which the agreement will initially run, joint research programmes will be set up in which part of the work will be done at the RAE and part at the university. The projects will in general be selected from those areas involving long term interests to the RAE where the university has or expects to have special expertise-these include electrical and control engineering, civil and mechanical engineering, materials technology and computing techniques. So far only about 60 per cent of the university has moved from the site at Battersea to Guildford, conveniently near the RAE, but, when the rest moves, departments such as the linguistics department, which offers intensive language courses, may become involved.

A joint RAE-university advisory board has been set up under the chairmanship of $\mathrm{Mr} \mathrm{R}$. J. Lee, the deputy director of RAE, and Professor D. R. Chick to initiate new joint projects and to carry out annual reviews of existing programmes. No attempt will be made rigidly to define the extent of the programmes.

RAE staff members will be able to work for higher degrees-M.Phil or PhD-from the university through any mutually acceptable research work, whether it is part of a joint research programme or not. They will also be encouraged to join the university Senior Common Room and any appropriate committees, while university members will be able to serve on the RAE planning bodies concerned with their work. Arrangements will be made for seconding members of staff of the university to RAE and vice versa for periods of up to a year. The RAE "will consider sympathetically" applications from research students to carry out their MSc projects at the RAE in areas of mutual interest. Some of the undergraduate sandwich course students will be able to spend their year in industry at the RAE. The university and RAE will cooperate in arrangements for holding specialist and refresher courses.

Schemes for forming links between Government establishments and universities go back to the early sixties. One of the first to be consummated was that between the University of Birmingham and the Royal Radar Establishment, Malvern, which brought about the exchange of three or four officers at a time. Much of the credit for that arrangement goes to Dr George MacFarlane, now Controller at the Ministry of Technology but then head of RRE. A link between the University of Southampton and the RAE was forged in 1966, and the following year the Explosives Research and Development Organization was linked with the University of East Anglia. The University of Surrey is anxious to make quite clear that the scheme now set up is more intimate than its predecessors. Whether it will be the first or the last of its kind is another matter. In spite of the platitudes of the Sutherland Committee, which reported on the relationship between Government establishments and the universities just two years ago, it is now more than likely that the Ministry of Technology is more anxious to have links with industry than with the universities.

\section{PLANNING \\ City for Learning}

Muton Keynes, the new city planned in an area of north Buckinghamshire about midway between London and Birmingham, moved a step nearer reality last week with the publication of the interim report of the consultants to the development corporation, LlewelynDavies, Weeks, Forestier-Walker and Bor. The planners aim to create a city for 250,000 people by the end of the century on a 21,000 acre $(8,863$ hectare) site taking in the existing towns of Bletchley, Wolverton and Stony Stratford and some other small villages including the one after which the city will take its 